\title{
VARIAÇÃO ESTRUTURAL QUANTITATIVA NO LENHO DE TERMINALIA IVORENSIS A. CHEV., COMBRETACEAE ${ }^{1}$
}

\author{
Cláudia V. Urbinati ${ }^{2}$ \\ Aristéa A. Azevedo ${ }^{3}$ \\ Eldo A. Monteiro da Silva ${ }^{3}$ \\ Pedro L. B. Lisboa ${ }^{2}$
}

Recebido em 16/08/2001. Aceito em 05/02/2003

\begin{abstract}
RESUMO - (Variação estrutural quantitativa no lenho de Terminalia ivorensis A. Chev., Combretaceae). Com o objetivo de analisar a variação anatômica ao longo do caule de Terminalia ivorensis, estudaram-se amostras de madeira de três indivíduos, nos planos radial e axial. Para tal, corpos de prova foram obtidos a partir de discos de madeira, de 2 em $2 \mathrm{~cm}$, no sentido medula-câmbio. A metodologia usada para desenvolver o trabalho foi aquela tradicionalmente recomendada para estudos em anatomia vegetal. A descrição anatômica realizada seguiu as recomendações do IAWA Committee. No sentido radial do caule, alguns elementos anatômicos apresentaram tendências de variação definidas e significativas estatisticamente quando aplicado o teste Tukey para comparação de médias. São eles: freqüência, diâmetro e comprimento dos elementos de vaso, freqüência de raios/mm linear, comprimento dos raios em número de células, e comprimento e espessura da parede das fibras. Já no sentido axial, todas as variáveis analisadas não se mostraram estatisticamente significativas. Os resultados observados devem-se, principalmente, à caracterização bem definida dos lenhos juvenil e adulto na madeira de Terminalia ivorensis.
\end{abstract}

Palavras-chave - Combretaceae, Terminalia ivorensis, variação anatômica quantitativa, xilema, lenho juvenil, lenho adulto

\begin{abstract}
Wood structural quantitative variation of the Terminalia ivorensis A. Chev., Combretaceae). In order to verify anatomical stem variation of the Terminalia ivorensis wood, were studied wood samples at three different heights in the radial and axial planes. Proof bodies were gotten at a $2 \mathrm{~cm}$ interval from the pith towards the vascular cambium. The utilized methodology to develop the job followed the traditionally recommended methodology for vegetable anatomy studies. The anatomical description followed the recommendations of the IAWA Committee. In the radial stem direction, some anatomic elements showed a well defined trend, which are statistically significant when using the Tukey test for measures comparison. They were: frequency, diameter and length of the vessel elements, ray frequency/linear mm, length of rays in number of the cells and fiber length and thickness. On the other side, in the axial stem direction, was not found anything statistically significant. This results were observed principally due the clear presence of the juvenile and adult wood in the lumber of Terminalia ivorensis.
\end{abstract}

Key words - Combretaceae, Terminalia ivorensis, anatomy quantitative variation, xylem, juvenile wood, adult wood

1 Parte da Dissertação de Mestrado da primeira Autora

2 MCT/ Museu Paraense Emílio Goeldi, Av. Magalhães Barata, 376, São Braz, C. Postal 399, CEP 66040-170, Belém, PA, Brasil (urbinati@museu-goeldi.br, plisboa@museu-goeldi.br)

3 Universidade Federal de Viçosa, Av. P. H. Holfs s/n, CEP 36571-000, Viçosa, MG, Brasil (esilva@mail.ufv.br, aazevedo@mail.ufv.br) 


\section{Introdução}

Dentre os trabalhos realizados em anatomia da madeira, os estudos sobre a variação na dimensão dos elementos celulares (traqueídes, fibras e elementos de vaso) são antigos, sendo realizados há pelo menos cem anos. O primeiro deles foi feito por Sanio (1872), que comparou em Pinus sylvestris L. (Pinaceae), o tamanho de traqueídes ao longo do caule e dos ramos. Todavia, os trabalhos que têm por objetivo avaliar a variação nas dimensões de elementos de vasos, fibras e raios, nos sentidos axial (baseápice) e radial (medula-câmbio), ao longo do caule de espécies que se desenvolvem em florestas de clima tropical ainda são poucos, comparativamente àqueles realizados com espécies de clima temperado.

Muitas investigações sobre variação quantitativa, no sentido radial, têm mostrado que o valor do comprimento celular no anel próximo à medula é pequeno, tanto para coníferas como para folhosas de florestas de clima temperado, porém aumenta rapidamente nos primeiros anéis e estabiliza após atingir um valor máximo (Silva 1992). Segundo Zobel \& Talbert (1984), as camadas de crescimento produzidas próximo à medula (lenho juvenil) têm características muito diferentes daquelas localizadas perto do câmbio (lenho adulto), posto que, aquelas camadas localizadas próximo à medula foram formadas durante o período de juvenilidade da árvore, no qual o ritmo de crescimento é mais acentuado. As camadas localizadas próximas ao câmbio foram formadas durante o período de maturidade da árvore. Além das diferenças anatômicas entre os lenhos juvenil e adulto, outros fatores como a idade, o vigor, as características genéticas do indivíduo e os fatores climáticos podem influenciar na variação da dimensão dos elementos celulares (Vysotskaya \& Vaganov 1989).

Em árvores de Acer pseudoplatanus L. (Aceraceae), Dodd (1984) encontrou acentuada diferença no tamanho dos elementos do lenho dentro das camadas de crescimento, principalmente no sentido radial. A área dos vasos em secção transversal, por exemplo, alcançou o máximo no meio da camada de crescimento e declinou no seu final. Já no sentido axial, o menor diâmetro do elemento de vaso foi encontrado na base do caule e dos ramos.

Wilkes (1988) relata que a variação no tamanho e na forma dos elementos celulares, no sentido axial, é aparentemente menos consistente do que no sentido radial do caule. Segundo Digby \& Wareing (1966), uma das causas que pode levar à variação longitudinal, como na frequiência de vasos, está relacionada à concentração de reguladores de crescimento, os quais têm importante participação na atividade cambial. Entretanto, os dados existentes envolvem poucas espécies.

Considerando-se a importância de estudar espécies de rápido crescimento, com a finalidade de substituir a exploração de espécies nativas, selecionou-se Terminalia ivorensis A. Chev. para desenvolver o presente trabalho.

Pertencente à família Combretaceae, T. ivorensis é conhecida vulgarmente no Brasil por "sete-copas"; na África Ocidental, de onde é originária, por "framiré" e, na Nigéria, por "idogbo". Segundo Barroso (1983), T. ivorensis ocorre em países como Camarões, Nigéria, Costa do Marfim, Gana, Libéria, Guiné e Togo. Essa espécie habita, predominantemente, regiões que apresentam precipitações uniformemente distribuídas entre 1.400 e $2.500 \mathrm{~mm}$ anuais, temperatura média anual de 23 a $27^{\circ} \mathrm{C}$ e umidade relativa do ar apenas excepcionalmente abaixo de $50 \%$, durante o período de seca. Em relação ao solo, a espécie ocorre, preferencialmente, em solos bem drenados até franco-argilosos, podendo se desenvolver também em solos franco-lateríticos e vulcânicos, entretanto não se desenvolve bem em solos com baixa capacidade de drenagem. Não ocorre em locais expostos a longas enchentes, contudo é tolerante a breves inundações (Lamprecht 1990). 
Devido às condições climáticas favoráveis, T. ivorensis adaptou-se muito bem a algumas regiões do Brasil e, por ser espécie de rápido crescimento (Coast 1946; Taylor 1962; Catinot 1965), vem sendo muito indicada para reflorestamento de áreas desmatadas (Lamprecht 1990). Sua madeira, comercialmente importante na África, pode ser usada para as mais diversas finalidades, principalmente para a carpintaria e, quando misturada a outras, pode ser utilizada na fabricação de papel. Além da aplicabilidade de sua madeira, alguns estudos com $T$. ivorensis têm revelado o seu alto valor medicinal (Iwu \& Anyanwu 1982).

O objetivo deste trabalho foi verificar a variação quantitativa de alguns elementos celulares constituintes do lenho, em diferentes alturas do caule de T. ivorensis, nos planos axial e radial, contribuindo para a caracterização da madeira da espécie.

\section{Material e métodos}

Os estudos anatômicos foram desenvolvidos nos Laboratórios de Anatomia Vegetal da Universidade Federal de Viçosa/UFV e de Anatomia de Madeira do Museu Paraense Emílio Goeldi/MPEG.

As amostras retiradas ao longo do caule de T. ivorensis foram obtidas de três indivíduos com 35 anos de idade cada, plantados em talhões, localizados no Setor de Silvicultura do Departamento de Engenharia Florestal da UFV. De cada indivíduo, foram coletadas amostras de madeira ao nível do DAP, as quais foram incorporadas no acervo da xiloteca Walter Alberto Egler do Museu Paraense Emílio Goeldi (MGx). Por não se encontrarem férteis, os materiais botânicos não foram incorporados ao herbário desta instituição. Os dados dendrométricos de cada indivíduo estão apresentados na tabela 1 .

Primeiramente foram retirados discos de madeira ao longo do caule, com aproximadamente $10 \mathrm{~cm}$ de espessura a 1,3; 11,3 e 21,3m de altura do nível do solo. Para o estudo no sentido radial, obteve-se a partir desses discos, cinquienta e quatro corpos de prova de 2 em $2 \mathrm{~cm}$, no sentido medula-câmbio (Fig. 1). Para avaliar a variação no sentido axial (base-ápice), foram selecionadas amostras a $2 \mathrm{~cm}$ do câmbio, nas três alturas analisadas.

A descrição macroscópica do lenho foi realizada com uma lupa de $10 \times$ de aumento, seguindo as normas do Instituto Brasileiro do Meio Ambiente e dos Recursos Naturais Renováveis - IBAMA (1992). A descrição microscópica seguiu as normas do IAWA Committee (1989). Os cortes histológicos foram obtidos com o auxílio de um micrótomo de deslize. Estes foram divididos em dois grupos, sendo um submetido à clarificação e coloração e o outro permanecendo ao natural para a observação de inclusões celulares. A coloração dos tecidos foi realizada de acordo com as técnicas usuais em Anatomia Vegetal (Johansen 1940). Para a obtenção do material macerado foi adotado o método de Franklin (1945).

As contagens e mensurações foram realizadas na porção central do corpo de prova

Tabela 1. Dados dendrométricos dos três indivíduos analisados de Terminalia ivorensis A. Chev. (Combretaceae).

\begin{tabular}{lcccccc}
\hline T. ivorensis & MGx & $\begin{array}{c}\text { Altura Total } \\
(\mathrm{m})\end{array}$ & $\begin{array}{c}\text { Altura do Fuste } \\
(\mathrm{m})\end{array}$ & $\begin{array}{c}\text { DAP a 1,3m } \\
\text { de alt. (cm) }\end{array}$ & $\begin{array}{c}\text { DAP a 11,3m } \\
\text { de alt. (cm) }\end{array}$ & $\begin{array}{c}\text { DAP a 21,3m } \\
\text { de alt. (cm) }\end{array}$ \\
\hline Indivíduo 01 & 7276 & 32 & 30 & 15,0 & 10,4 & 8,0 \\
Indivíduo 02 & 7301 & 30 & 29 & 12,6 & 9,0 & 6,6 \\
Indivíduo 03 & 7302 & 29 & 28 & 12,5 & 8,3 & 6,4 \\
\hline
\end{tabular}


(área de $1 \mathrm{~cm}$ ) e de forma aleatória entre os lenhos primaveril e estival. A descrição e as contagens e mensurações das estruturas foram realizadas em cortes histológicos e em material macerado com o auxílio de um sistema de análise digital. No corpo de prova de cada local amostrado, realizou-se para cada variável analisada (elementos de vasos - freqüência $/ \mathrm{mm}^{2}$, comprimento e diâmetro; raios - altura em número de células e em micrômetros, frequiência/mm linear; fibras - comprimento, espessura da parede e largura do lume), 25 contagens e medições, das quais obtiveram-se os valores médio, máximo, mínimo, desviopadrão, coeficiente de variação, erro padrão e intervalo de confiança. Para avaliar o grau de
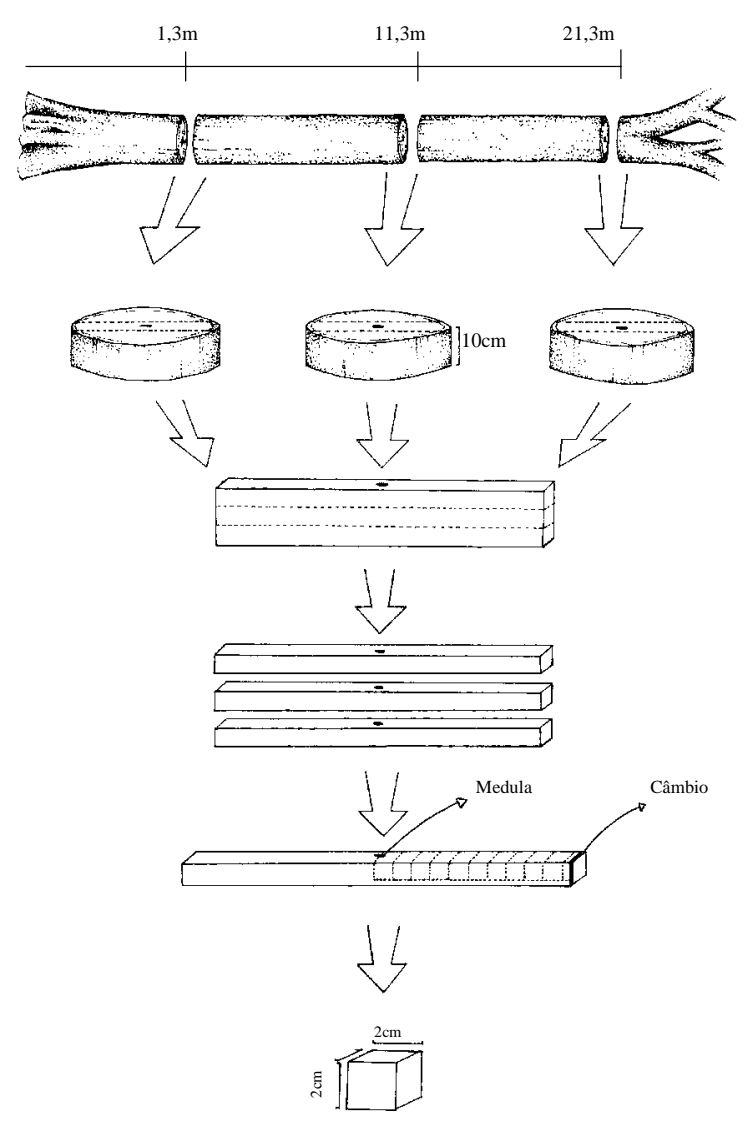

Figura 1. Esquema de retirada das amostras de discos de madeira e corpos de prova, ao longo do caule de Terminalia ivorensis A. Chev., a 1,3; 11,3 e 21,3m de altura. significância da variação, aplicou-se o teste Tukey para comparação de médias. Para as variáveis que se apresentaram significativas, aplicou-se um teste de regressão para verificar a tendência de variação.

\section{Resultados e discussão}

Descrição do lenho de Terminalia ivorensis A. Chev. - Observou-se pelo aspecto geral de uma secção transversal do tronco de T. ivorensis, que as camadas de crescimento produzidas no período juvenil da árvore e localizadas próximo à medula, apresentam a distância entre os anéis de crescimento bem maior do que aqueles produzidos durante a idade adulta da mesma árvore e que estão localizados próximo ao câmbio vascular (Fig. 2).

O lenho da espécie apresenta camadas de crescimento distintas, formadas principalmente pelo espessamento da parede das fibras e eventualmente por anéis semiporosos (Fig. 3-4). Vasos com distribuição difusa, secção transversal circular; predominantemente solitários $(63,2 \%)$, seguidos de múltiplos com 2-3 células $(34,4 \%)$ e em séries de 4 ou mais células $(2,3 \%)$; numerosos, em média 15,2 vasos $/ \mathrm{mm}^{2}(5-52)$ (Tab. 2); com diâmetro médio de 122,4 $\mu \mathrm{m}$ (31,7-272,5) (Tab. 2) (Fig. 4-5); elementos de vaso com comprimento médio de $424,6 \mu \mathrm{m}$ (147,8-790,5) (Tab. 2); apêndices às vezes presentes em uma ou em ambas as extremidades; placa de perfuração simples, levemente oblíqua (Fig. 6-7); pontoações intervasculares areoladas, com disposição alterna; pontoações radiovasculares com duas formas distintas (Fig. 8-9); tilos pouco freqüentes. Parênquima axial paratraqueal vasicêntrico, eventualmente confluente, unindo 2-4 vasos devido a proximidade dos vasos (Fig. 10-11), observou-se parênquima apotraqueal difuso escasso com 5-8 células por série. Raios fusionados $(7,8 \%)$, encontrados próximos à medula a 11,3 e $21,3 \mathrm{~m}$ de altura do caule (Fig. 12-13). Entretanto, predominam os raios 


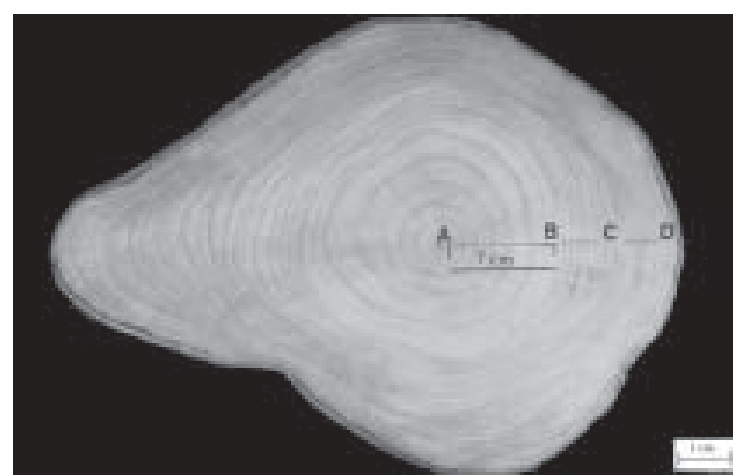

Figura 2. Aspecto geral de uma seção transversal do tronco de Terminalia ivorensis, revelando cerne e alburno indistintos. A. medula; A-B. região que compreende o lenho juvenil; B-C. região de transição entre os lenhos juvenil e adulto; C-D. região que compreende o lenho adulto.

simples $(92,1 \%)$ em todas as amostras (Fig. 14); bisseriados (58\%), seguidos dos trisseriados $(26,8 \%)$ e unisseriados $(15,3 \%)$; predominantemente heterogêneos, sendo o corpo constituído por células procumbentes e a margem por uma fila de células quadradas ou eretas (Fig. 15); frequiência média de 9,1 por mm linear (5-19) (Tab. 2); altura média de 12,2 células (3-41) e de $310 \mu \mathrm{m}(101,6-904,4)$ (Tab. 2). Fibras libriformes com pontoações simples ou extremamente reduzidas, não-septadas, curtas a moderadamente longas, com comprimento médio de 1.048,6 4 m $(484,5-1.682,8)$ (Tab. 2); largura média do lume de $13,0 \mu \mathrm{m}(3,4-26,8) \mathrm{e}$ espessura média da parede de 2,6 $4 \mathrm{~m}$ (1-6) (Tab. 2).

Variação anatômica - Vasos: Frequiência por $\mathrm{mm}^{2}$ - no sentido radial do caule de T. ivorensis, observou-se que a frequiência de vasos $/ \mathrm{mm}^{2}$ diminuiu até aproximadamente $7 \mathrm{~cm}$ de distância da medula, nas diferentes alturas analisadas $(1,3$; 11,3 e 21,3m). Na região mais próxima à copa, considerado nesse trabalho "ápice", a redução nos valores foi menos proeminente, mas significativa. Já no meio e na base, observou-se redução proeminente na frequiência até $7 \mathrm{~cm}$ da medula, estabilizando-se (com flutuações mínimas) nas distâncias seguintes em direção ao câmbio. $O$ padrão de variação é bem representado na região do caule considerada mais "adulta", a 1,3m de altura do caule. Quando aplicado o teste Tukey para comparação de médias, observou-se que os valores encontrados próximos a medula, diferem estatisticamente daqueles encontrados próximos ao câmbio. Essas diferenças foram significativas ao nível de 5\% de probabilidade $(\mathrm{F}=11,6267 ; \mathrm{p}=0,000)$. Por outro lado, comparando-se as amostras retiradas apenas próximos ao câmbio nas três alturas ao longo do caule, observou-se quantidade maior de vasos em direção ao ápice da árvore, porém essa variação não foi significativa $(F=0,0346$; $\mathrm{p}=0,966)$ (Fig. 16 e 25).

A tendência de variação observada no sentido medula-câmbio pode estar marcando o término do lenho juvenil na espécie, que abrange em torno de $5-7 \mathrm{~cm}$ da medula, aproximadamente, e o início do lenho adulto, caracterizado por valores mais estáveis. Resultados semelhantes

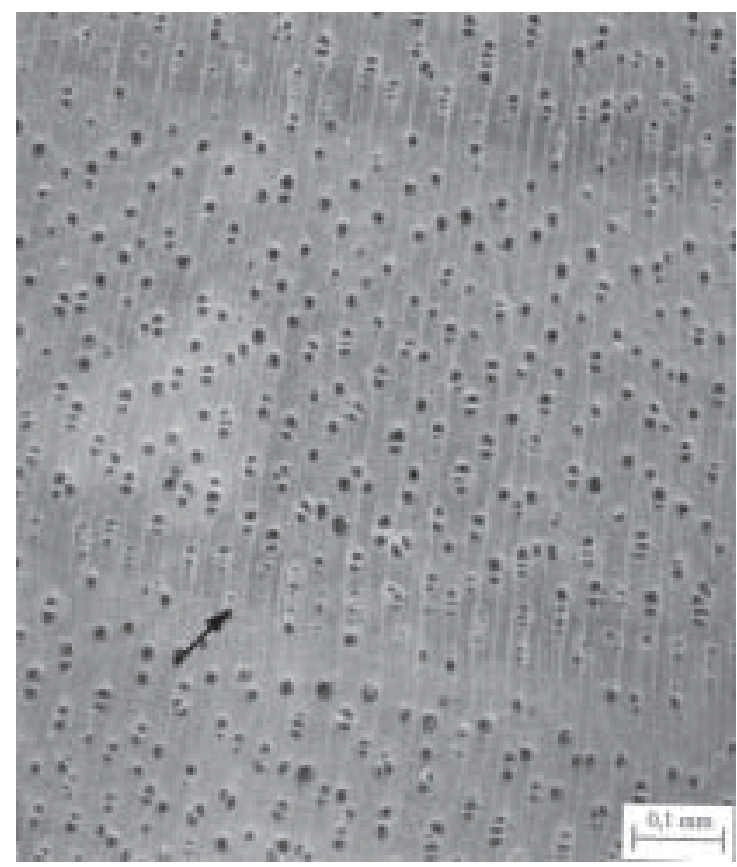

Figura 3. Fotomacrografia do lenho de Terminalia ivorensis em secção transversal. Camadas de crescimento delimitadas principalmente pelo espessamento da parede das fibras. 

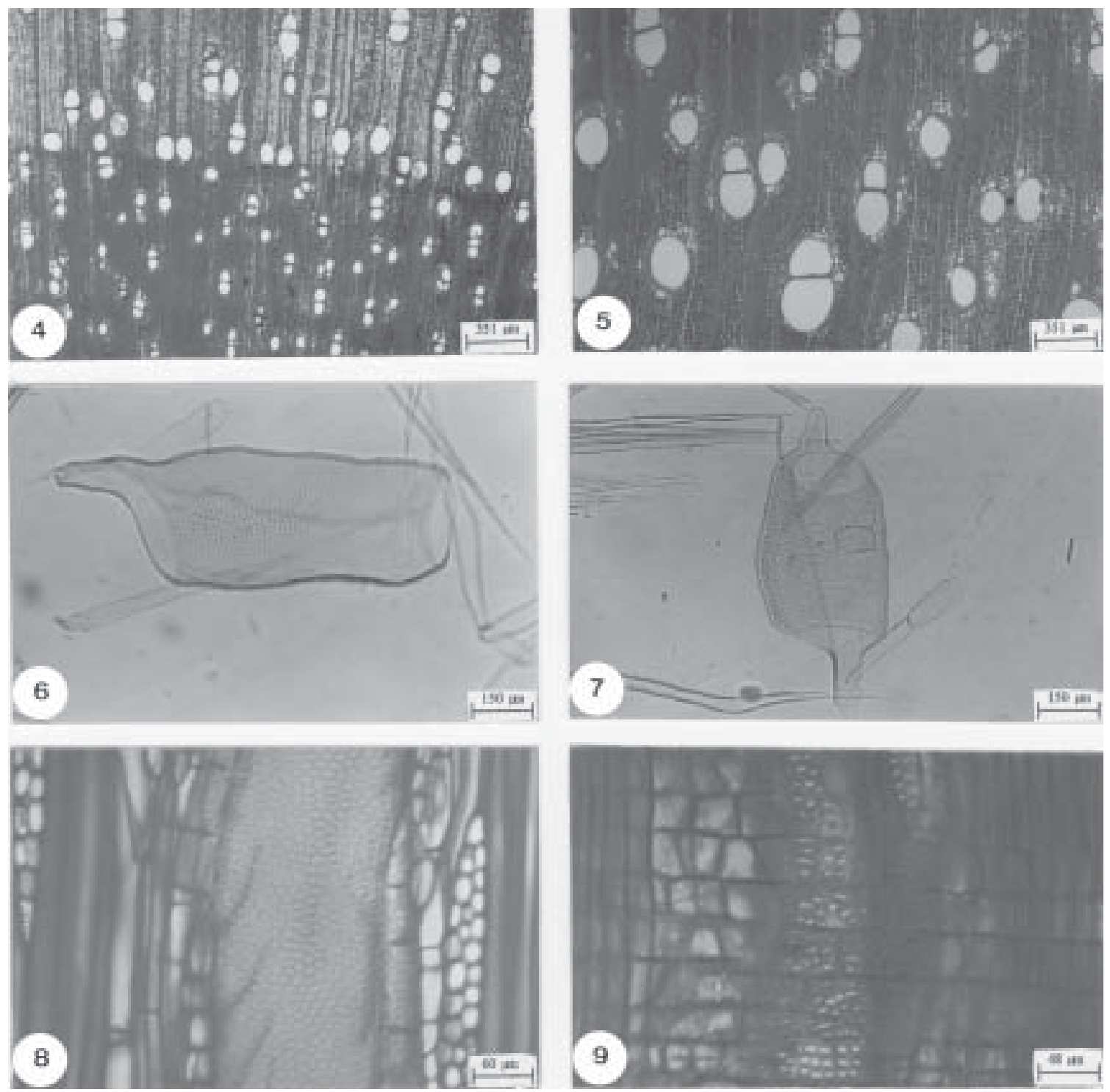

Figuras 4-9. Fotomicrografias da madeira de Terminalia ivorensis. 4. Secção transversal: camada de crescimento delimitada pelo espessamento da parede das fibras e por anéis semi-porosos, vasos com diâmetro reduzido próximo à medula. 5 . Vasos com maior diâmetro próximo ao câmbio vascular. 6-7. Lenho dissociado: elementos de vaso com placa de perfuração simples e apêndice em uma (6) ou em ambas as extremidades (7). 8. Secção longitudinal tangencial: pontoações intervasculares areoladas em disposição alterna. 9. Secção longitudinal radial: pontoações radiovasculares com duas formas distintas no mesmo raio. 

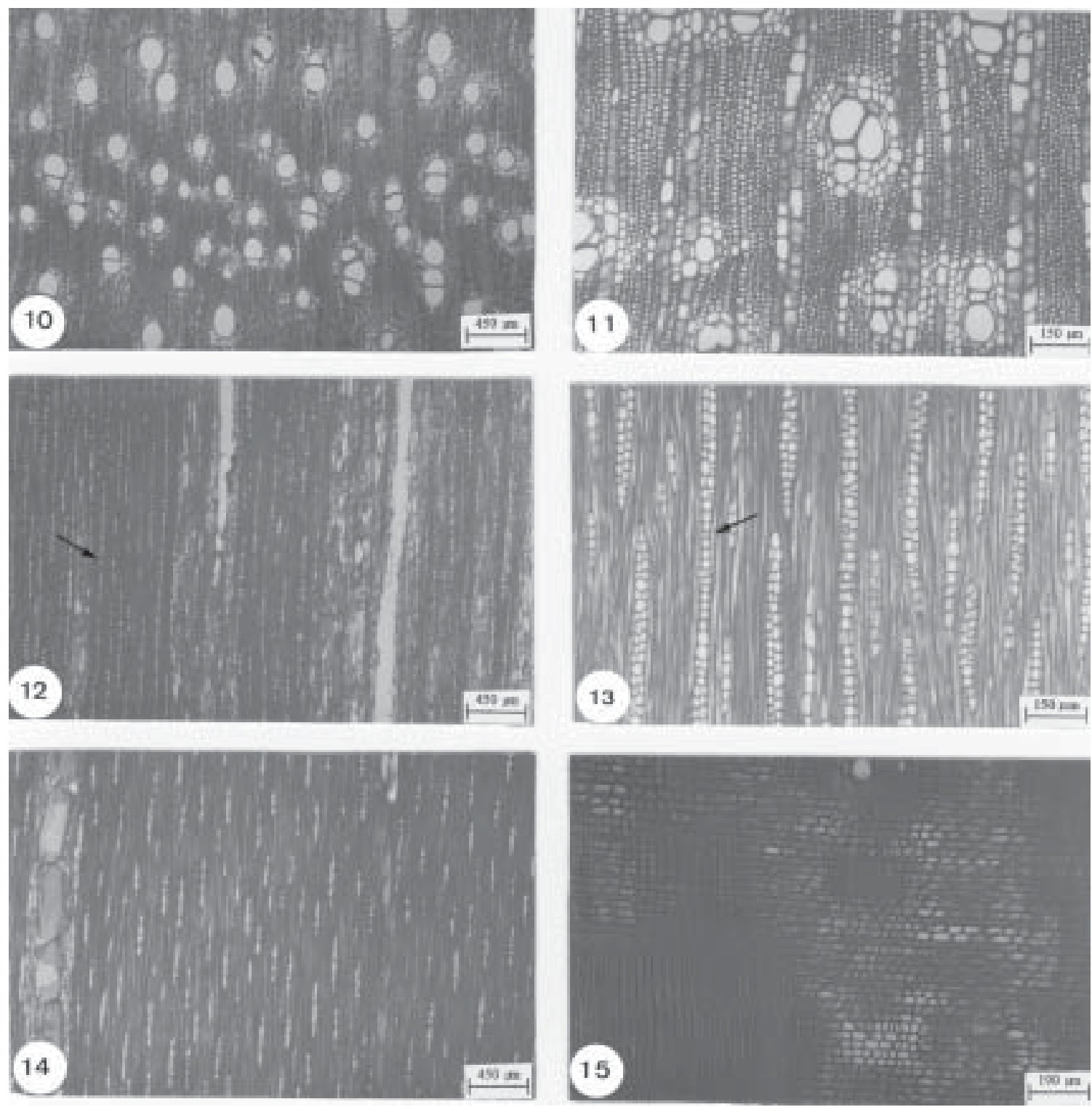

Figuras 10-15. Fotomicrografias da madeira de Terminalia ivorensis. 10-11. Secção transversal mostrando parênquima axial vasicêntrico. 12-13. Secção longitudinal tangencial: raios fusionados encontrados principalmente a 11,3 e 21,3 metros de altura do caule, próximo à medula. 14. Secção longitudinal tangencial: raios simples observados a 1,3m do nível do solo, próximo ao câmbio vascular. 15. Secção longitudinal radial: composição heterocelular dos raios. 
Tabela 2. Ficha biométrica de Terminalia ivorensis A. Chev. (Combretaceae).

\begin{tabular}{|c|c|c|c|c|c|c|c|c|c|c|c|}
\hline \multirow{3}{*}{$\begin{array}{l}\text { Elementos } \\
\text { anatômicos }\end{array}$} & \multirow{3}{*}{$\begin{array}{l}\text { N. de contagens } \\
\text { e medições }\end{array}$} & \multirow{3}{*}{$\begin{array}{l}\text { Unidade } \\
\text { de medida }\end{array}$} & \multicolumn{9}{|c|}{ Valores determinados } \\
\hline & & & \multirow[t]{2}{*}{ Máx. } & \multirow[t]{2}{*}{ Mín. } & \multirow[t]{2}{*}{$\bar{x}$} & \multirow[t]{2}{*}{ S } & \multirow[t]{2}{*}{$\mathrm{CV}(\%)$} & \multirow[t]{2}{*}{$S \bar{x}$} & \multicolumn{3}{|c|}{$\mathrm{IC} \alpha_{5 \%}$} \\
\hline & & & & & & & & & Lim. Inf. & & Lim. Sup. \\
\hline \multicolumn{12}{|l|}{ Vasos } \\
\hline Freqüência & 25 & $\mathrm{n} . / \mathrm{mm}^{2}$ & 52,0 & 5,0 & 15,2 & 4,3 & 28,5 & 0,9 & 13,4 & - & 16,9 \\
\hline Comprimento & 25 & $\mu \mathrm{m}$ & 790,5 & 147,8 & 424,6 & 92,8 & 21,9 & 18,6 & 386,3 & - & 463,0 \\
\hline Diâmetro & 25 & $\mu \mathrm{m}$ & 272,5 & 31,7 & 122,4 & 31,9 & 26,0 & 6,4 & 109,3 & - & 135,6 \\
\hline \multicolumn{12}{|l|}{ Raios } \\
\hline Freqüência & 25 & n./mm linear & Ir $\quad 19,0$ & 5,0 & 9,1 & 1,5 & 16,5 & 0,3 & 8,5 & - & 9,8 \\
\hline Altura & 25 & $\mu \mathrm{m}$ & 904,4 & 101,6 & 310,0 & 100,9 & 32,6 & 20,2 & 268,3 & - & 351,7 \\
\hline Altura & 25 & n. de células & s 41,0 & 3,0 & 12,2 & 4,9 & 40,2 & 1,0 & 10,2 & - & 14,2 \\
\hline \multicolumn{12}{|l|}{ Fibras } \\
\hline Comprimento & 25 & $\mu \mathrm{m}$ & $1.682,8$ & 484,5 & $1.048,6$ & 163,6 & 15,6 & 32,7 & 981,1 & - & $1.116,2$ \\
\hline Largura do lume & 25 & $\mu \mathrm{m}$ & 26,8 & 3,4 & 13,0 & 2,5 & 19,6 & 0,5 & 12,0 & & 14,1 \\
\hline Espessura da parede & e 25 & $\mu \mathrm{m}$ & 6,0 & 1,0 & 2,6 & 0,6 & 23,0 & 0,1 & 2,3 & - & 2,8 \\
\hline
\end{tabular}

$\bar{x}$ - Média; S - Desvio padrão; CV (\%) - Coeficiente de variação; S̄̄ - Erro padrão da média; $I C \alpha_{5 \%}$ - Intervalo de confiança

ao encontrado no presente estudo foram observados por Dadswell (1958), Sarkany \& Stieber (1958), Knigge \& Koltzenburg (1965), Giroud (1977), Foekel et al. (1983), Butterfield et al. (1993) e Bosman et al. (1994). Por outro lado, Silva (1992) não constatou variação no sentido radial quanto à freqüência de vasos no lenho de Saccoglotis guianensis Benth. (Humiriaceae). O resultado observado na variação axial foi semelhante àquele encontrado por Silva (1992), em Saccoglotis guianensis Benth. (Humiriaceae) e Andira parviflora Ducke (Leg. Papilionoideae).

Diâmetro transversal dos elementos de vaso inversamente à frequiência de vasos, que diminuiu no sentido radial do tronco, o diâmetro dos vasos apresentou aumento e posterior tendência à estabilização nesse sentido, nas diferentes alturas analisadas. Da mesma forma, quando aplicado o teste estatístico, os dados observados próximos à medula diferiram estatisticamente daqueles encontrados próximos ao câmbio. A tendência de variação foi, portanto, significativa ao nível de $5 \%$ de probabilidade $(\mathrm{F}=19,3202 ; \mathrm{p}=0,000)$. De modo geral, a variação encontrada pode ser atribuída à presença dos lenhos juvenil e adulto no caule de T. ivorensis. Ao longo do caule, essa estrutura apresentou variações mínimas que não diferiram estatisticamente ao nível de 5\% de probabilidade ( $F=0,1096 ; p=0,898)$ (Fig. 17 e 26).

A mesma tendência encontrada no sentido radial do caule foi observada por Giroud (1977), Fukazawa \& Ohtani (1982), Bosman et al. (1994), Helinska (1995) e Bosman (1996). A distinção entre os lenhos juvenil e adulto, pode, em algumas espécies, ser impossível de definir com base na freqüência e diâmetro dos elementos de vaso. Butterfield et al. (1993) não observaram variação no diâmetro dos elementos de vaso em Hieronyma alchorneoides Allemao (Euphorbiaceae) e Vochysia guatemalensis Donn. Sm. (Vochysiaceae). Bosman (1996), analisando a variação longitudinal em Shorea leprosula Miq. e S. pauciflora King. (Dipterocarpaceae), observou que a média no diâmetro dos elementos de vaso também seguiu padrão pouco consistente, mas muitas árvores mostraram aumento a partir da base em direção ao ápice, e somente duas das árvores analisadas apresentaram redução em torno de $10 \mathrm{~m}$ de altura do caule. 
Comprimento dos elementos de vaso observou-se no sentido radial que os menores valores estão localizados próximos à medula. Nas distâncias seguintes houve aumento e tendência à estabilização. Os elementos de vaso próximos à medula diferiram estatisticamente daqueles localizados próximos ao câmbio quanto ao comprimento. Essa diferença no sentido medulacâmbio foi significativa ao nível de $5 \%$ de probabilidade $(\mathrm{F}=7,3313 ; \mathrm{p}=0,000)$. No sentido axial, as diferenças observadas nas três alturas analisadas não diferiram estatisticamente entre si ao nível de 5\% de probabilidade ( $\mathrm{F}=5,4430$; $\mathrm{p}=0,545)$ (Fig. 18 e 27).

Os resultados observados em $T$. ivorensis foi semelhante àqueles encontrados por Giroud (1977) e Foekel et al. (1983). Fukazawa \& Ohtani (1982), estudando a variação anatômica em Tilia japonica (Miq.) Simonk. (Tiliaceae), observaram que a 5,30m de altura do caule, o comprimento dos elementos de vaso aumentou no sentido medula-câmbio e, depois de alcançar valor máximo, estabilizou. Em outras alturas, a variação foi muito pequena. Por outro lado, Silva (1992) encontrou em Andira parvifolia Ducke (Leguminosae Papilionoideae) maior comprimento dos elementos de vaso nas proximidades da medula do que próximo ao câmbio. Iqbal \& Ghouse (1983) avaliaram a média do comprimento dos elementos de vaso em Prosopis spicigera L. (Leguminosae Mimosoideae), encontrando aumento inicial a partir do câmbio em direção à medula, e declínio gradual, com algumas flutuações, próximo à medula. Silva (1992) observou no sentido axial do caule de Andira parvifolia Ducke (Leguminosae Papilionoideae) a mesma tendência de variação encontrada no presente trabalho, com algumas irregularidades.

Os diferentes estudos realizados com elementos de vaso revelam que, cada espécie, dada as suas características genéticas e às condições ambientais nas quais se desenvolvem, apresentam padrões anatômicos diferentes, podendo ou não apresentar nitidamente os lenhos juvenil e adulto.
Raios - Freqüência por mm linear - observou-se na região do caule mais próxima à copa das árvores redução nessa variável. No meio e na base do caule, a redução até $7 \mathrm{~cm}$ da medula ocorreu de forma sutil, apresentando em seguida, valores estáveis. Os valores observados próximos à medula diferiram estatisticamente daqueles encontrados próximos ao câmbio. Estas diferenças foram significativas ao nível de $5 \%$
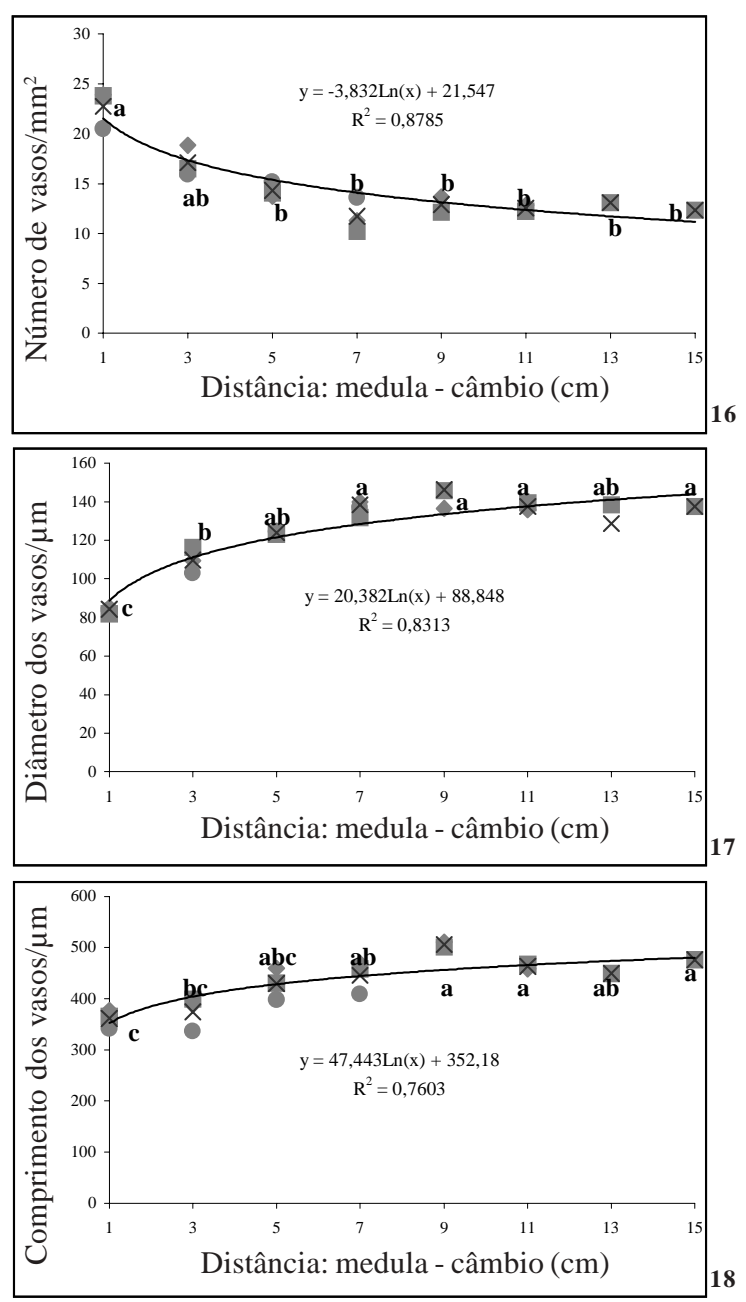

Figuras 16-18. Variação radial dos elementos de vaso na base $(1,3 \mathrm{~m})$, meio $(11,3 \mathrm{~m})$ e ápice $(21,3 \mathrm{~m})$ do caule de Terminalia ivorensis A. Chev. Médias seguidas pela mesma letra não diferem estatisticamente ao nível de $5 \%$ de probabilidade. 16. Freqüência/mm². 17. Diâmetro. 18. Comprimento. Legenda: - Base; - Meio; - Ápice; $x$ - Tendência; - - Log da tendência. 
de probabilidade $(\mathrm{F}=4,1592 ; \mathrm{p}=0,003)$. No sentido axial, a variação ao longo do caule não foi significativa, e também, não foi possível definir um padrão de variação $(\mathrm{F}=3,9469 ; \mathrm{p}=0,081)$ (Fig. 19 e 28).

Os resultados encontrados em $T$. ivorensis, no sentido radial, estão de acordo com aqueles observados por Giroud (1977) em Entandrophragma utile (Dawe \& Sprague) Sprague (Meliaceae). A redução na freqüência de raios próximo ao câmbio, observada no presente estudo, pode ser conseqüência da redução do número de iniciais radiais, com o aumento do número de iniciais fusiformes e, conseqüente, aumento na proporção de fibras nessa região.

Altura em micrômetros e em número de células - quanto à variação radial na altura dos raios em micrômetros, observou-se que essa medida não variou ao longo da distância medulacâmbio, em qualquer altura analisada. Pôde-se observar através da linha de tendência que os valores nesse sentido não diferiram estatisticamente entre si $(F=0,9990 ; p=0,451)$. Considerando, contudo, a altura dos raios em número de células, observou-se que no ápice (a $21,3 \mathrm{~m}$ de altura), essa variável apresentou redução acentuada em seus valores, onde os maiores foram encontrados a $1 \mathrm{~cm}$ da medula, reduzindo-se rapidamente até $3 \mathrm{~cm}$, estabilizandose a partir daí. A 11,3 e a $1,3 \mathrm{~m}$ de altura do caule, os valores apresentaram reduzido grau de flutuação. As medidas observadas próximos à medula diferiram estatisticamente das demais. Essa variável apresentou-se estatisticamente significativa, devido à presença de raios compostos por células de tamanho reduzido próximos à medula $(\mathrm{F}=6,5453 ; \mathrm{p}=0,000)$ (Fig. 20-21). No sentido axial, tanto para altura dos raios em micrômetros quanto para altura em número de células, os menores valores foram observados na base, aumentando no meio e reduzindo em direção ao ápice. Contudo, a variação entre as médias foi pequena e não significativa $(F=0,2387 ; \mathrm{p}=0,795 \mathrm{e} F=2,8742$; $\mathrm{p}=0,133$, respectivamente) (Fig. 29-30).

Analisando-se os raios, observou-se também nas alturas estudadas, percentual maior de raios fusionados na região mais próxima à medula, reduzindo em direção ao câmbio. Conseqüentemente, houve freqüência muito reduzida de raios simples próximos à medula, estabilizandose em seguida. No sentido axial, não foi observada tendência de variação para essas variáveis. O teste estatístico mostrou que, no sentido radial, houve diferença significativa entre os valores encontrados próximos à medula $\mathrm{e}$ aqueles observados próximos ao câmbio. Já no sentido axial essa diferença não foi observada $(F=8,4696 ; p=0,000$ e $F=3,8652 ; p=0,083$, respectivamente).

Fibras - Comprimento - vários trabalhos já foram realizados com o objetivo de avaliar a variação no comprimento das fibras no sentido radial ao longo do caule. Em Terminalia ivorensis, o comprimento apresentou a 11,3 e 21,3 metros de altura, aumento (com flutuações) e posterior estabilidade. Predominou entre os três indivíduos pequena redução dos valores próximos ao câmbio em todas as alturas analisadas. Esses valores diferiram estatisticamente daqueles observados próximos ao câmbio $(\mathrm{F}=3,6298$; $\mathrm{p}$ $=0,006$ ). Devido às pequenas flutuações nos valores observados nos pontos analisados no sentido axial do caule, os valores não diferiram entre si, não podendo-se definir uma tendência de variação $(\mathrm{F}=3,1082 ; \mathrm{p}=0,118)$ (Fig. $22 \mathrm{e}$ 31). Os resultados observados são semelhantes aos encontrados por Bisset \& Dadswell (1958), Hamilton (1961), Parameswaran \& Liese (1974), Giroud (1977), Fukazawa \& Ohtani (1982), Foekel et al. (1983), Bhat et al. (1989) e Trugilho et al. (1996).

Largura do lume - Não foi possível definir uma tendência de variação, uma vez que a variabilidade entre os dados, tanto no sentido radial quanto no axial, foi mínima. Os valores observados nos dois sentidos não diferiram esta- 
tisticamente entre si $(F=0,9618 ; p=0,476$ e $F=$ 2,2149; $\mathrm{p}=0,190$, respectivamente) (Fig. 23 e 32).

Espessura da parede - os resultados mostraram que para essa variável, os valores encontrados próximos à medula, diferiram estatisticamente daqueles localizados próximos ao câmbio $(\mathrm{F}=2,2274 ; \mathrm{p}=0,060)$. Já no sentido axial, os

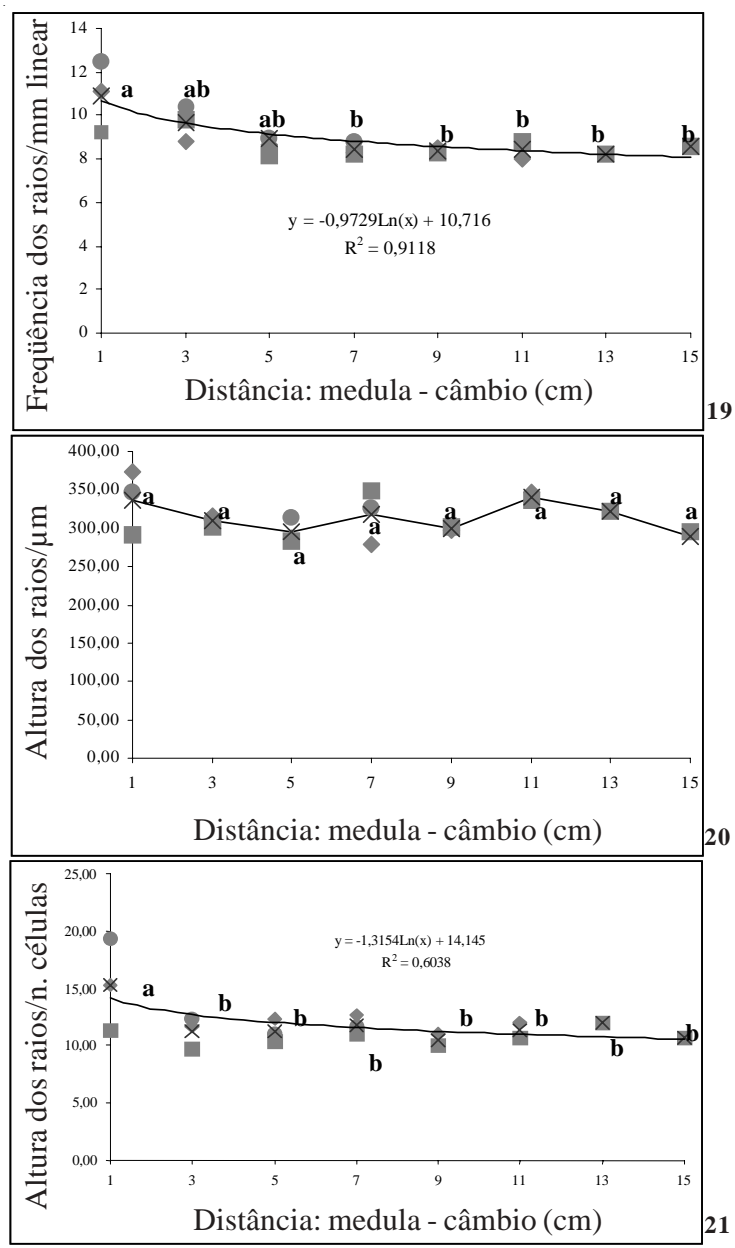

Figuras 19-21. Variação radial dos raios na base $(1,3 \mathrm{~m})$, meio $(11,3 \mathrm{~m})$ e ápice $(21,3 \mathrm{~m})$ do caule de Terminalia ivorensis A. Chev. Médias seguidas pela mesma letra não diferem estatisticamente ao nível de $5 \%$ de probabilidade. 19. Freqüência/mm linear. 20 - 21. Altura em micrômetros e em número de células, respectivamente. Legenda: $\mathbf{0}$ Base; - Meio; - Ápice; $\times$ - Tendência; —- Log da tendência. valores encontrados não diferiram estatisticamente entre as alturas analisadas $(\mathrm{F}=0,3411$; $\mathrm{p}=0$,724) (Fig. 24 e 33).

Segundo Tsoumis (1968), a variação na estrutura anatômica da madeira é influenciada pela idade do câmbio vascular. Assim, três períodos de desenvolvimento do câmbio são reconhecidos: $1^{\circ}$ - período de juvenilidade, $2^{\circ}$ -

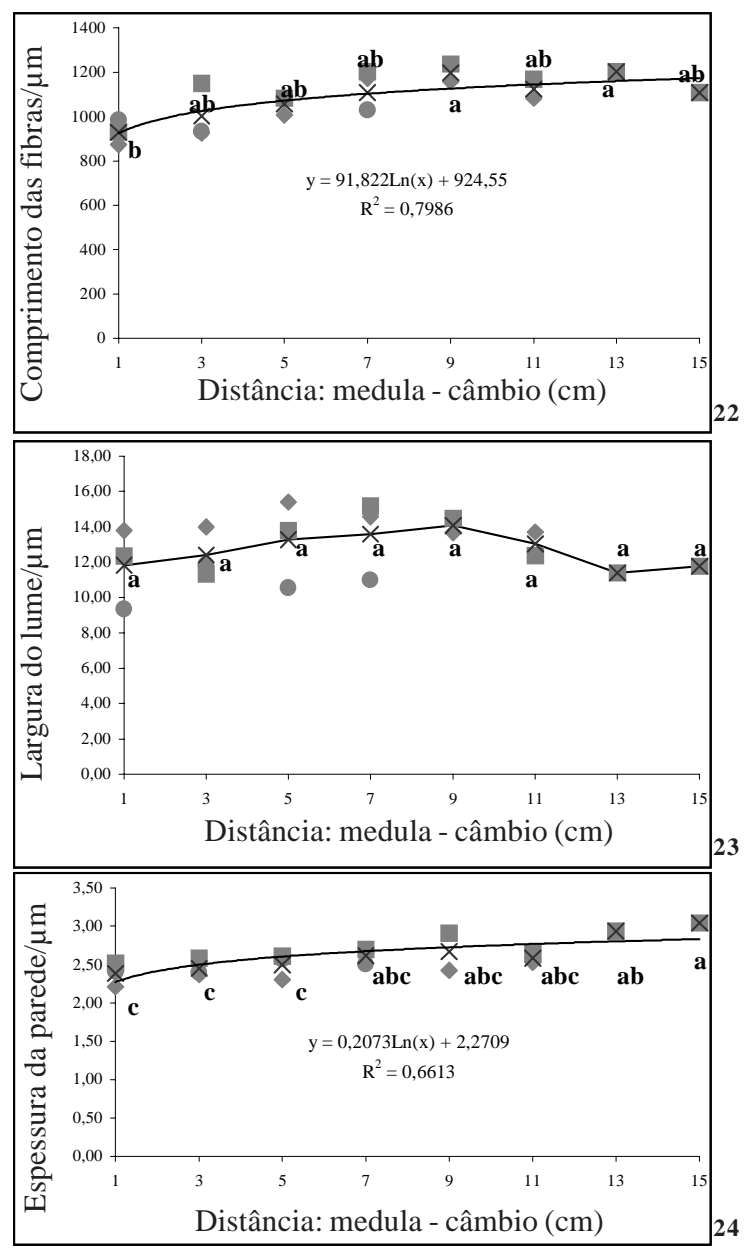

Figuras 22-24. Variação radial das fibras na base $(1,3 \mathrm{~m})$, meio $(11,3 \mathrm{~m})$ e ápice $(21,3 \mathrm{~m})$ do caule de Terminalia ivorensis A. Chev. Médias seguidas pela mesma letra não diferem estatisticamente ao nível de $5 \%$ de probabilidade. 22. Comprimento. 23. Largura do lume. 24. Espessura da parede. Legenda: - Base; - Meio; - Ápice; $x$ - Tendência; —- Log da tendência. 
período de maturidade ou fase adulta, e $3^{\circ}$ período de senescência. Para Zobel \& Talbert (1984), a duração desses períodos é difícil de ser determinada e, em algumas espécies, a mudança do lenho juvenil para o adulto pode ser abrupta, enquanto que em outras, pode ser muito gradual.

No presente estudo, o padrão de variação radial observado na freqüência, diâmetro e comprimento dos elementos de vaso, na freqüência de raios/mm linear, no comprimento dos raios
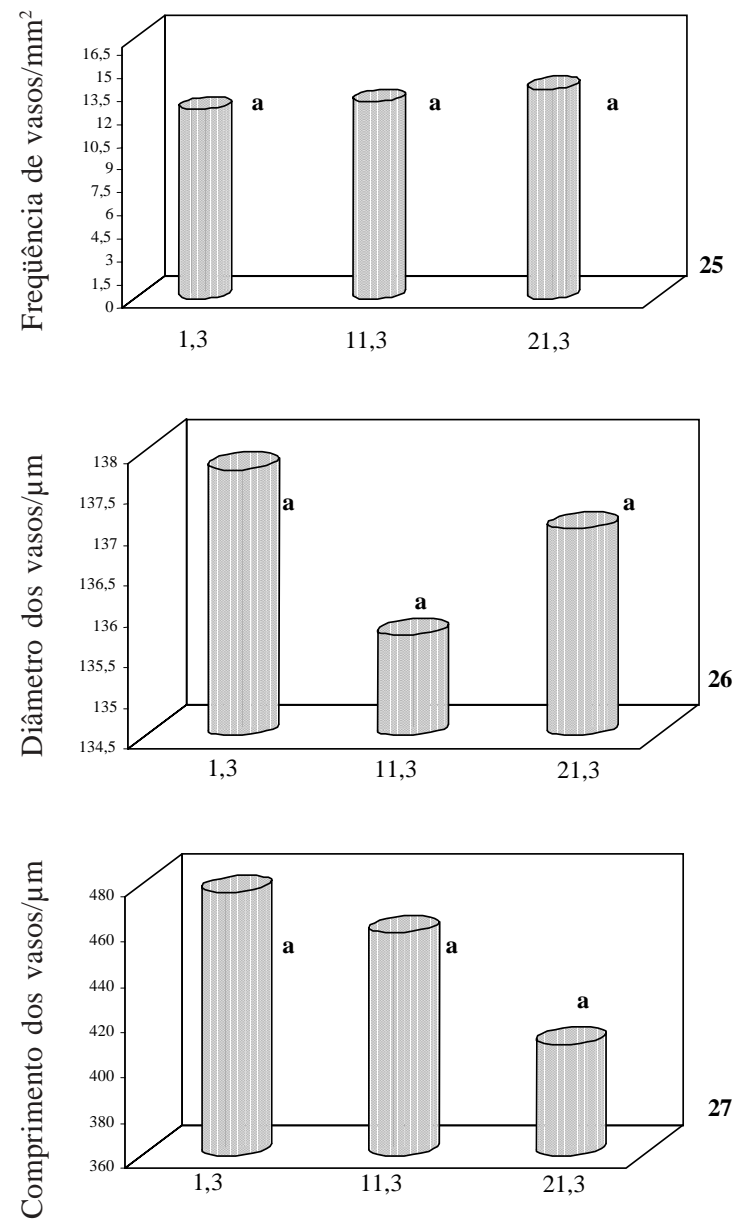

Alturas ao longo do caule (metros)

Figuras 25-27. Variação axial dos elementos de vaso ao longo do caule de Terminalia ivorensis A. Chev. Médias seguidas pela mesma letra não diferem estatisticamente ao nível de $5 \%$ de probabilidade. 25. Freqüência/ $/ \mathrm{mm}^{2}$. 26. Diâmetro. 27. Comprimento. em número de células, no percentual de raios fusionados e simples e no comprimento e espessura da parede das fibras, indicam que a região do lenho juvenil na madeira de T. ivorensis estudada abrange até aproximadamente $5-7 \mathrm{~cm}$ de distância da medula e, a partir desse ponto, predomina o lenho adulto.

Tsoumis (1968) define o lenho juvenil como sendo a madeira que compreende a região mais próxima à medula, estendendo-se da base até o ápice da árvore. Consequientemente, o ápice da
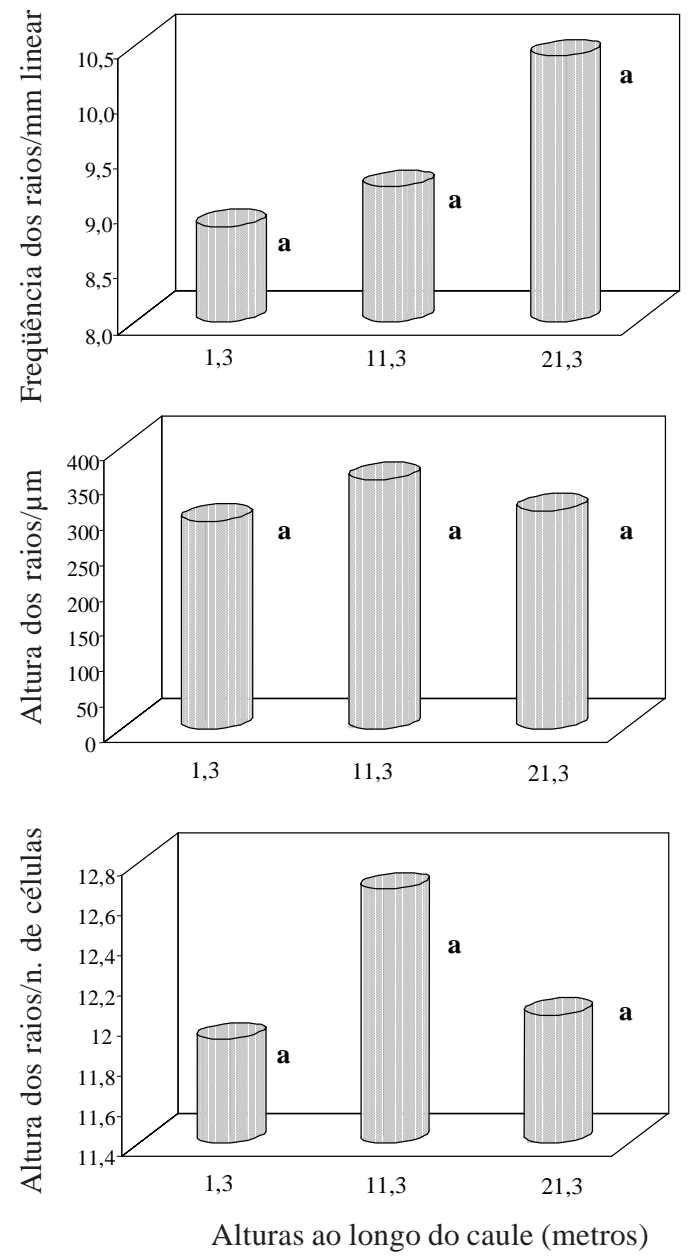

30

Figuras 28-30. Variação axial dos raios ao longo do caule de Terminalia ivorensis A. Chev. Médias seguidas pela mesma letra não diferem estatisticamente ao nível de 5\% de probabilidade. 28. Freqüência/mm linear. 29-30. Altura em micrômetros e em número de células, respectivamente. 
árvore consiste principalmente de lenho juvenil, enquanto que na base da mesma árvore, a maior proporção é de lenho adulto. Zobel \& Talbert (1984) explicaram que o lenho juvenil resulta da elevada quantidade de reguladores de crescimento e carboidratos próximos à região do ápice. Mallan (1995) menciona que algumas características do lenho juvenil são: menor diâmetro celular, maior freqüência de vasos $/ \mathrm{mm}^{2}$, menor comprimento de vasos e fibras e paredes celulares mais finas. Davidson
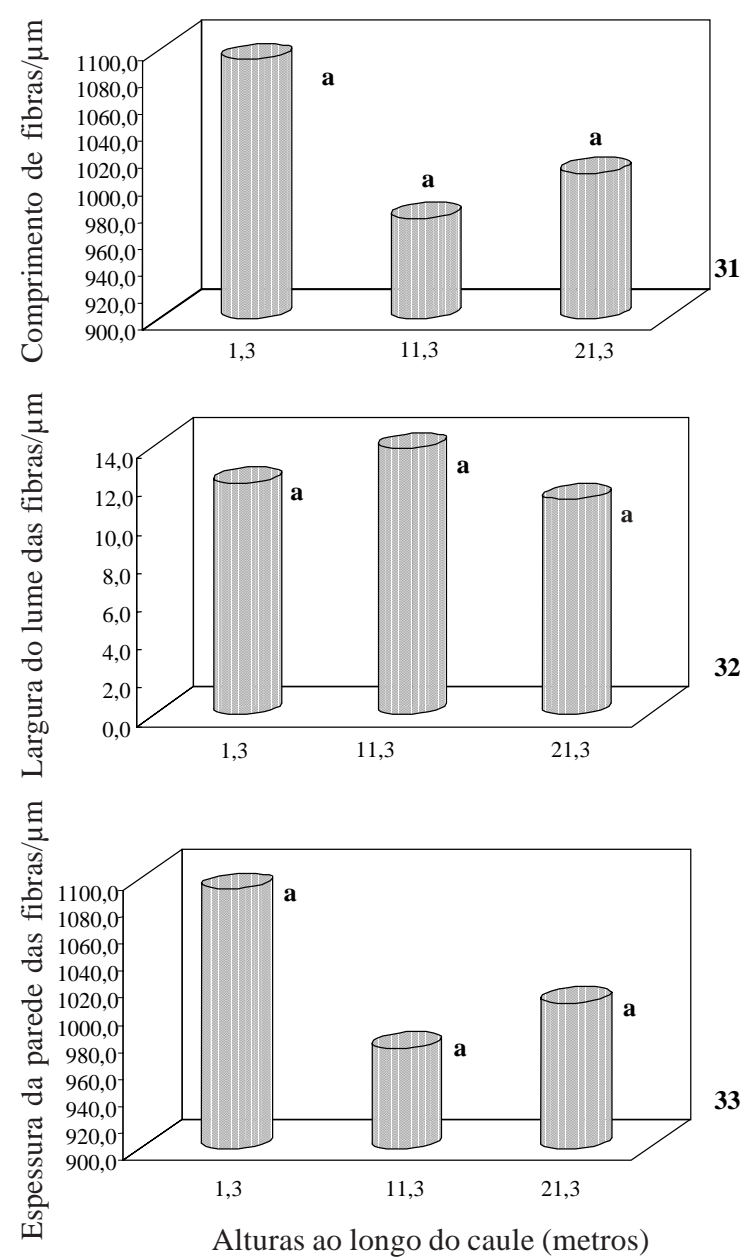

Figuras 31-33. Variação axial das fibras ao longo do caule de Terminalia ivorensis A. Chev. Médias seguidas pela mesma letra não diferem estatisticamente ao nível de 5\% de probabilidade. 31. Comprimento. 32. Largura do lume. 33. Espessura da parede.
(1972) explicou a rápida redução na freqüência de vasos nos primeiros $8 \mathrm{~cm}$ da medula pela diferença anatômica, principalmente quantitativa, entre os lenhos juvenil e adulto. No lenho juvenil a frequiência de vasos é mais elevada, pois o ritmo de crescimento no período de juvenilidade é mais acentuado.

A causa da variação radial no comprimento dos elementos de vaso a 1,3m de altura do caule de T. ivorensis pode estar relacionada também com a idade do câmbio. Segundo alguns autores (Bailey 1923; Bosshard 1951; Ghouse \& Yunus 1972; Ghouse \& Hasmi 1980), as iniciais fusiformes aumentam em tamanho com o aumento da idade do câmbio mas, ao alcançarem valor máximo, tornam-se relativamente estáveis. $\mathrm{O}$ aumento no comprimento dos elementos de vaso a 11,3 e a $21,3 \mathrm{~m}$ de altura foi irregular. Isso deveu-se, provavelmente, à pouca idade do câmbio nessas regiões da árvore, nas quais as iniciais fusiformes ainda não atingiram a maturidade, fase em que os valores são mais estáveis.

O período de juvenilidade do desenvolvimento da madeira é seguido pela formação do lenho adulto, caracterizado pela obtenção de um típico nível de organização estrutural, em que ocorre maior estabilidade nas atividades fisiológicas, influenciando, assim, a atividade do câmbio vascular e, refletindo-se conseqüentemente na estrutura anatômica da madeira (Tsoumis 1968). Entretanto, como mencionado por Vysotskaya \& Vaganov (1989), o vigor e as características genéticas do espécime, fatores climáticos, entre outros, também podem influenciar no tamanho celular.

Apesar de, no presente estudo, algumas variáveis terem apresentado tendência de variação definida, outras apresentaram-se sem tendência. Essas também não mostraram diferenças significativas entre as distâncias nos sentidos medula - câmbio e base - ápice, como por exemplo o comprimento dos raios em micrômetros. Siddiqi (1991) menciona que a distribuição das iniciais radiais de diversas 
larguras e alturas pode ser muito influenciada pela variação sazonal, então, raios com várias alturas e larguras formam uma população mista. Esse autor, estudando o impacto da variação sazonal sobre a estrutura e atividade do câmbio vascular em Ficus religiosa L. (Moraceae), observou que os raios unisseridados e as pequenas iniciais radiais são mais abundantes no período ativo do que na fase de inatividade do câmbio.

O fator que pode ter levado às flutuações no comprimento das fibras, observadas no presente estudo, pode, entre outros, estar relacionado às divisões pseudotransversais. Em muitas madeiras, exceto aquelas que têm iniciais fusiformes curtas, a divisão anticlinal, na face tangencial, ocorre de tal maneira que a formação da parede entre as duas células filhas é oblíqua. As divisões deste tipo são geralmente descritas como pseudotransversais. Os dois produtos de uma divisão pseudotransversal não são usualmente do mesmo comprimento e, no começo, ambas são mais curtas do que a inicial que as originou. Entretanto, após a divisão, elas aumentam em comprimento, tornado-se mais longas do que a célula inicial (Metcalfe \& Chalk 1989). Estudos têm revelado que o comprimento das iniciais cambiais, derivadas de divisões pseudotransversais, diminui quando a frequiência de divisões pseudotransversais das iniciais cambiais aumenta (Bannam 1955; 1965; 1967). Essa evidência indica que o comprimento das fibras também pode estar relacionado com a razão de divisões pseudotransversais das iniciais cambiais.

Além disso, diferenças anatômicas entre indivíduos podem ocorrer no mesmo local, entre locais, na mesma localidade ou entre diferentes localidades geográficas e altitudes. Segundo Trugilho et al. (1996), as variações na composição química, física e anatômica da madeira são grandes entre espécies, embora ocorram dentro da mesma espécie, em função principalmente da idade, de fatores genéticos e ambientais. Tem sido demonstrado que certas características da estrutura da madeira são inalteráveis. Entretanto, a separação entre as causas genéticas ou ambientais é difícil de ser distinguida (Tsoumis 1968).

Outro ponto a ser levado em consideração, ao analisar-se a variação axial, são os hormônios de crescimento. Mesmo não sendo analisado no presente estudo, sabe-se que a auxina exerce papel predominante na regulação da atividade cambial, incluindo mitoses nas iniciais fusiformes e diferenciação das cambiais derivadas. Ao longo do caule, usualmente ocorre transporte basípeto de auxina e freqüentemente se observa maior número de vasos no ápice próximo à copa da árvore. Em árvores onde se observa a queda das folhas, a síntese de auxina é interrompida, refletindo-se na redução da atividade cambial (Kozlowski \& Pallardy 1997).

Admitindo que a diferenciação dos elementos vasculares é controlada por um fluxo polar e basípeto de auxina, Zimmermann \& Potter (1983) e Aloni (1995) explicaram mudanças no tamanho e na frequiência dos vasos ao longo do caule. Entre elas podem-se citar: 1 . a elevada freqüência de vasos $/ \mathrm{mm}^{2}$ está associada à alta concentração de auxina, diminuindo do ápice para a base; 2 . interrupção no fluxo de auxina ao longo do caule causa aumento local em sua concentração, promovendo o aumento do número de vasos naquele local; 3. a duração da diferenciação de vasos aumenta do ápice em direção à base da árvore; 4. o diâmetro dos vasos é regulado pela taxa de diferenciação: de uma rápida diferenciação resultam vasos estreitos e, de uma diferenciação mais lenta, resultam vasos largos.

No presente estudo, as variações observadas no sentido axial são consideradas mínimas e sem significância estatística, uma vez que os locais selecionados para a análise encontravam-se em região próxima ao câmbio, sendo assim já localizada no lenho adulto, onde a variação é pequena.

Os resultados observados no presente estudo no sentido axial, também podem estar 
relacionados com as flutuações no comprimento das iniciais cambiais ao longo do caule, pois tratam-se de iniciais cambiais em diferentes idades de funcionamento. Em uma árvore, no sentido axial, existe um câmbio com diferentes idades. Por exemplo, em um caule, o câmbio com 100 anos localiza-se mais próximo à base da árvore, e o câmbio com 1 ano, localiza-se no ápice da mesma árvore. Câmbios de idades intermediárias existem em várias alturas ao longo do caule da árvore. Segundo Iqbal \& Ghouse (1983), existe pequena variação com flutuações no comprimento da inicial cambial ao longo do caule, o que pode ter provocado as flutuações nas dimensões das variáveis analisadas no presente estudo.

Através dos resultados deste trabalho, conclui-se que em $T$. ivorensis os lenhos juvenil e adulto são bem definidos, caracterizados radialmente pela freqüência, diâmetro e comprimento dos elementos de vaso, frequiência de raios/mm linear, altura dos raios em número de células, raios simples e fusionados e, pelo comprimento e espessura da parede das fibras. No sentido axial, a variação na dimensão dessas estruturas não se mostrou significativa. A caracterização bem definida dos lenhos juvenil e adulto pode ser atribuída às características genéticas da espécie.

\section{Agradecimentos}

Agradecemos ao Conselho Nacional de Desenvolvimento Científico e Tecnológico (CNPq), pelo auxílio financeiro; aos técnicos da Universidade Federal de Viçosa e do Departamento de Botânica do Museu Paraense Emílio Goeldi, pelo apoio durante o desenvolvimento do trabalho.

\section{Referências bibliográficas}

Aloni, R. 1995. The induction of vascular tissues by auxin and cytokinin. Pp. 531-546. In: P. J. Davies (Ed.). Plant hormones: physiology, biochemistry and molecular biology. 2. ed. Kluwer Academic, Netherlands.
Bailey, I. W. 1923. The cambium and its derivative tissue. IV-The increase in girth of the cambium. American Journal Botany 10: 499-509.

Bannan, M. W. 1955. The vascular cambium and radial growth in Thuja occidentalis. Canadian Journal of Botany 33: 113-138.

Bannan, M. W. 1965. The length, tangencial diameter, and length with ratio of conifer tracheids. Canadian Journal of Botany 43: 967-984.

Bannan, M. W. 1967. Anticlinal divisions and cell length in conifer cambium. Forestry Production Journal 17: 63-69.

Barroso, A. B. 1983. Silvicultura especial de árboles maderables tropicales. Ministério da Cultura, Habana.

Bhat, K. M.; Bhat, K. V. \& Dhamodaran, T. K. 1989. Fibre length variation in stem and branches of eleven tropical hardwoods. IAWA Bulletin 10: 63-70.

Bisset, I. J. W. \& Dadswell, H. E. 1949. The variation of fibre-length within one tree of Eucalyptus regmans F. V. M. Australian Forestry 13: 86-96.

Bosman, M. T. M. 1996. Longitudinal variation in selected wood properties of naturally and plantation grown light red meranti (Shorea leprosula and $S$. parviflora, Dipterocarpaceae). IAWA Journal 17: 5-14.

Bosman, M. T. M.; Kort, I. de; Genderen, M. K. van \& Baas, P. 1994. Radial variation in wood properties of naturally and plantation grown light red meranti (Shorea sp., Dipterocarpaceae). IAWA Journal 15: 111-120.

Bosshard, H. H. 1951. Variabilität der elemente der eschenholzes in funktion von der kambiumtätigkeit. Schweizerische Zeitschrift für Forstwesen 102: 648-665.

Butterfield, R. P.; Crook, R. P.; Adans, R. \& Morris, R. 1993. Radial variation in wood specific gravity, fibre length and vessel area for two Central American hardwoods: Hyeronima alchorneoides and Vochysia guatemalensis: natural and plantation - grown trees. IAWA Journal 14: 153-161.

Catinot, R. 1965. Sylviculture tropicale em forêt dense africaine. Bois et Forêts des Tropiques 103: 3-16.

Coast, G. 1946. Report of the forestry department for the year 1944-1945. Forestry Abstracts 7: 297.

Dadswell, H. E. 1958. Wood structure variations occurring during tree growth and their influence on properties. Journal Institute Wood Science 1: 11-33. 
Davidson, J. 1972. Variation, association and inheritance of morfological and wood characters in a improvement programe for Eucalyptus deglupta. Tese de Doutorado. Universidade de Melbourne.

Digby, J. \& Wareing, P. F. 1966. The relationship between endogenous hormone levels in the plant and seasonal aspects of cambial activity. Annals of Botany 120: 607-622.

Dodd, R. S. 1984. Radial and tangential diameter variation of wood cells within trees of Acer pseudoplatanus. IAWA Bulletin 5: 253-257.

Foekel, C. E. B.; Busnardo, C. A.; Dias, C.; Schmidt, C.; Silva, R. M. R. \& Vesz, J. B. V. 1983. Variabilidade radial da madeira de Eucalyptus saligna. Silvicultura 28: 726-731.

Franklin, G. L. 1945. Preparation of thin sections of synthetic resins and wood - resin composites, and a new macerating method for wood. Nature 155: 51.

Fukazawa, K. \& Ohtani, J. 1982. Within a tree variation of wood element size in Tilia japonica. IAWA Bulletin 3: 201-205.

Ghouse, A. K. M. \& Yunus, M. 1972. Some aspects of cambial development in shoots of Dalbergia sissuo Roxb. Flora (Jena) 162: 549-558.

Ghouse, A. K. M. \& Hasmi, S. 1980. Changes in vascular cambium of Polyanthia longifolia Benth et Hook in relation to the girth of the tree. Flora (Jena) 170: 135-143.

Giroud, B. 1977. Statistical analysis of wood structure variation as related to distance from the pith in Entandrophragma utile (Meliaceae). IAWA Bulletin 4: 71-75.

Hamilton, J. R. 1961. Variation of wood properties in sourthern red oak (Quercus falcata Michx.). Forestry Prodution Journal 11: 267-271.

Helinska, R. L. 1995. Variation of vessel lumen diameter in radial direction as na indication of the juvenile wood growth in oak (Quercus petraea Liebl.). Forestry Abstracts 56: 610.

Iawa Committee. 1989. List of microscope features for hardwood identification. IAWA Bulletin 10: 234-332.

Instituto Brasileiro do Meio Ambiente e dos Recursos Naturais Renováveis-IBAMA. 1992. Normas para procedimentos em estudos de anatomia de madeira: I. Angiospermae, II. Gimnospermae. Brasília, Série Técnica, 15.

Iqbal, M. \& Ghouse A. K. M. 1983. An analytical study on cell size variation in some arid zone trees of India: Acacia nilotica and Prosopis spicigera. IAWA Bulletin 4: 46-52.
Iwu, M. M. \& Anyanwu, B. N. 1982. Anti-inflammatory and anti-arthritic properties of Terminalia ivorensis. Fitoterapia 53: 25-34.

Johansen, D. A. 1940. Plant microtechnique. McGraw-Hill, New York.

Knigge, W. \& Koltzenburg, C. 1965. The influence of timber qualities and ecological conditions on the cell sizes and on the proportions of types of cell in hardwoods in the temperate zone. Proceedings-IUFRO 2: 1- 24.

Kozlowski, T. T. \& Pallardy, S. G. 1997. Growth control in woody plants. 3. ed. Academic Press, New York.

Lamprecht, H. 1990. Silvicultura nos trópicos: ecossistemas florestais e respectivas espécies arbóreas - possibilidades e métodos de aproveitamento sustentado. Deutsche Gesellschaft für Technische Zusammenarbeit. Eschborn.

Mallan, F. A. 1995. Eucalyptus improvement for lumer production. Pp. 1-19. In: Anais do Seminário Internacional de Utilização da Madeira de Eucalipto para Serraria. IPEF/IPT, São Paulo.

Metcalfe, C. R. \& Chalk, L. 1989. Anatomy of the dicotyledons. v.2. 2 ed. Clarendon, Oxford.

Parameswaran, N. \& Liese, W. 1974. Variation of cell length in bark and wood of tropical tree. Wood Science Technology 8: 81-90.

Sanio, K. 1872. Ueber die Grösse der Holzzellen bei der gemeinen Kiefer (Pinus sylvestris L.). Jahrbbusch Wissenschaftliche Botanik 8: 401-420.

Sarkany, S. \& Stieber, J. 1958. Preliminary notes on the quantitative anatomy of the wood in Fagus sp. Acta Biologica Academiae Scientiarum Hungariae. Suplll. 2: 13.

Siddiqi, T. O. 1991. Impact of seasonal variation on the structure and activity of vascular cambium in Ficus religiosa. IAWA Bulletin 12: 177-185.

Silva, C. A. 1992. Variação dimensional dos elementos xilemáticos em duas espécies madeireiras da Amazônia. Acta Amazonica 22: 261-274.

Taylor, C. J. 1962. Tropical forestry with particular reference to West Africa. Oxford University, London.

Trugilho, P. F.; Lima, J. T. \& Mendes, L. M. 1996. Influência da idade nas características físicoquímicas e anatômicas da madeira de Eucalyptus saligna. Revista Cerne 2: 94-11.

Tsoumis, G. 1968. Wood as raw material. Pergamon Press, Oxford. 
Vysotskaya, L. G. \& Vaganov, E. A. 1989. Components of the variability of radial cell size in tree rings of conifers. IAWA Bulletin 10: 417-428.

Wilkes, J. 1988. Variations of wood anatomy within species of Eucalyptus. IAWA Bulletin 9: 13-23.
Zimmermann, M. H. \& Potter, D. 1983. Vessel - lenght distribution in branches, stem and roots os Acer rubrum L. IAWA Bulletin 3: 103-109.

Zobel, B. \& Talbert, J. 1984. Applied forest tree improvement. John Wiley \& Sons, New York. 